\title{
MISSÕES DE PESQUISA: INVENTARIANDO A DOCUMENTAÇÃO ESCOLAR DO SERTÃO BAIANO
}

\author{
Vânia Muniz dos Santos \\ Universidade do Estado da Bahia \\ vaniamuniz@ymail.com \\ Antonieta Miguel \\ Universidade do Estado da Bahia \\ antonietamiguel40@yahoo.com.br
}

\begin{abstract}
RESUMO
O Projeto Missões de Pesquisa: levantamento e catalogação de fontes sobre a História da Educação no interior baiano consiste em ações que viabilizem o inventário e a construção de um banco de dados sobre a documentação escolar dispersa entre arquivos de diferentes natureza e envolve discentes, docentes e egressos do Departamento de Ciências Humanas DCH - Campus VI, da Universidade do Estado da Bahia. O projeto se iniciou em 2014, como desdobramento das atividades do Núcleo de Pesquisa sobre História Social e Prática de Ensino (NHIPE) e do Laboratório de Pesquisa e Didática da História (LAPEDHI) e já realizou quatro viagens de campo para municípios circunvizinhos. Os documentos localizados foram fotografados e catalogados em ficha específica, posteriormente estas informações são digitadas, formando um banco de dados que será disponibilizado para pesquisadores da área. A necessidade de conservação de documentos relacionados e advindos de escolas em quaisquer ambientes é de extrema importância para as pesquisas na temática. Alguns resultados já foram alcançados com as Missões, entre eles duas monografias que discutem a História da Educação e das Instituições escolares, bem como, três projetos de pesquisa na temática, dois projetos de iniciação científica e produções científicas como artigos e relatos de experiência apresentados em eventos regionais e internacionais. Dessa maneira, o Projeto Missões de Pesquisa: levantamento e catalogação de fontes sobre a História da Educação no interior baiano contribui para a difusão e proteção do patrimônio histórico educativo da Bahia ao inventariar documentos escolares dispersos que servirão de fonte para futuras pesquisas.
\end{abstract}

Palavras-chaves: História da Educação. Missões de Pesquisas. Inventários. Documentação Escolar.

\section{SEARCH MISSIONS: INVENTORYING DOCUMENTATION OF SCHOOL SERTÃO BAIANO}

\begin{abstract}
The Project Mission Research: survey and cataloging of sources on the History of Education in Bahia inside consists of actions that enable inventory and building a database on school documentation dispersed among files of different nature and involves students, teachers and graduates of the Department of Humanities - DCH - Campus VI, the Bahia State University. The project began in 2014 as a development of the activities of the Research Group on Social History and Teaching Practice (NHIPE) and Research Laboratory and Teaching of History (LAPEDHI) and has held four field trips to surrounding municipalities. Localized documents
\end{abstract}


were photographed and cataloged in a specific form, then this information is entered, forming a database that will be made available to researchers. The need for conservation and related documents coming from schools in any environment is of utmost importance for research in the subject. Some results have already been achieved with the Missions, including two monographs discussing the History of Education and school institutions, as well as three research projects in the thematic two undergraduate research projects and scientific production as articles and experience reports presented in regional and international events. Thus, the Mission Research Project: raising and sources of cataloging on the History of Education in Bahia inside contributes to the dissemination and protection of the educational heritage of Bahia to the inventory dispersed school documents that will serve as a source for future research.

Keywords: History of Education. Research missions. Inventories. School documentation.

\section{O PROJETO MISSÕES DE PESQUISA, SUA PROPOSTA}

O presente texto objetiva apresentar o trabalho desenvolvido por um grupo de pesquisadores da Universidade do Estado da Bahia - Campus VI, com fontes para a História da Educação no interior da Bahia. O Projeto Missões de Pesquisa: levantamento e catalogação de fontes sobre a História da Educação no interior baiano se insere nas ações do Núcleo de Pesquisa sobre História Social e Prática de Ensino (NHIPE) e do Laboratório de Pesquisa e Didática da História (LAPEDHI) e respondem aos objetivos propostos por ambos no que concerne à pesquisa, ensino e extensão, sendo que suas atividades abrigam alunos de vários semestres do curso de História.

Desde sua criação, em 2012, as ações dos pesquisadores do LAPEDHI detectaram a incipiência de pesquisas, no curso de História, que elegessem a educação, incluindo o ensino de História, como objeto investigativo. Esta situação, a nosso ver, impedia compreender lacunas na História de homens e mulheres moradores dos chamados sertões baianos (considerados lugares distantes da capital em termos geográficos, econômicos e de desenvolvimento sócio-político). Um dos problemas percebidos consistia na incapacidade dos graduandos em identificar fontes para a temática. Em parte, por considerarem temas tradicionais da historiografia (por exemplo: escravidão, poder local) como mais significativos, por isso importantes, no fazer do historiador; por outra, por desconhecerem os arquivos escolares, suas fontes e as características específicas da investigação histórico-educacional.

Diante da demanda posta, o Projeto Missões de Pesquisa: levantamento $e$ catalogação de fontes sobre a História da Educação no interior baiano, iniciado em 2014, foi pensado para promover ações que viabilizem o inventário e a construção de um banco de 
dados sobre a documentação escolar dispersa entre arquivos de diferentes natureza, envolvendo discentes, docentes e egressos e consolidando, dessa forma, as pesquisas sobre a temática no Departamento de Ciências Humanas - DCH - Campus VI, da Universidade do Estado da Bahia ${ }^{1}$.

\section{A EDUCAÇÃO, O ENSINO E A PROBLEMÁtiCA DE INVESTIGAÇÃo HISTÓRICA}

Segundo Delgado (2005, p. 211):

No puede plantearse en profundidad la problemática de la investigación históricoeducativa, sin antes plantearse la misma cuestión con respecto a la História en general. Las historias sectoriales son, ante todo, Historia, y el oficio de historiador de la educación es, sin ninguna clase de complejos, oficio de historiador. (DELGADO, 2005, p. 211).

Isto posto, afirmamos nossa posição de que a educação e o ensino também são objetos da História e necessitam de procedimentos de análise documental oriundos da investigação histórica. Com base nesta perspectiva, o Projeto Missões oportuniza aos graduandos o contato com fontes específicas e se coloca como uma possibilidade de ampliação de pesquisas sobre a temática, além de lançar diferentes olhares sobre a História da Educação na Bahia.

Algumas questões características da investigação histórico-educativa são relevantes para o desenvolvimento da pesquisa. Dentre as ideias mais difundidas entre os pesquisadores de História da Educação estão: (i) a necessidade de promover o cruzamento de fontes, a (ii) existência de documentos fora dos arquivos escolares e do acervo escolar e (iii) a dispersão das fontes em diferentes lugares, mesmo nos arquivos públicos, de modo geral, os documentos encontram-se em fundos variados.

Velasco (2011) ao discorrer sobre fotografias escolares nos dá uma base para compreender que os documentos que contam a história das instituições escolares e da própria educação estão muito para além dos seus muros.

\footnotetext{
${ }^{1}$ Os professores Luciana Oliveira Correia, Genilson Ferreira dos Santos e Fernanda Oliveira de Matos, membros do LAPEDHI e ligados ao NHIPE e ao PROMEBA - Projeto Memória da Educação na Bahia, além de contribuir com o Projeto Missões, desenvolvem pesquisas e projetos próprios que compartilham do objetivo de fortalecer as linhas de pesquisa sobre História da Educação e do Ensino.
} 
[...]. Em los archivos familiares las fotografias escolares de los membros son considerados antes que nada <<fotos de recuerdo >> [...], uma serie de câmbios posibles de uso y admiten tratamento personalizadores. Estas _las escolares_de gestam como rutinas de escuela, algunas como parte de laaccion institucional de registro, identificacion e integración de los alunos; otras, como produto de devolucón a las famílias a modo de imagem oficiosa, es decir, institucionalizda, de uno de seus membros. (VELASCO, 2011, p. 18).

As fotografias citadas pelo autor são só um exemplo frente a grande quantidade de documentos sobre a educação que estão fora dos arquivos escolares e que recebem outras interpretações fora deles.

No entanto, percebemos que a problemática que envolve os documentos e os arquivos escolares está relacionada a processos mais complexos que as de ordem de localização e organização destas fontes. Dizem respeito ao lugar que a escola e tudo que ela produz, inclusive documentos, ocupa na sociedade.

A relação da sociedade estabelecida com as instituições escolares na atualidade pode ser caracterizada como utilitária; a ela cabe a função de "preparar" crianças e jovens para o mundo, principalmente, o do trabalho. As pessoas no presente não concebem as escolas como materiais da memória coletiva (LE GOFF, 1990), ou seja, não representam uma herança do passado, capaz de contribuir com a cultura de um povo.

Por outro lado, também para a academia e poder público, é a condição de invisibilidade que este lugar assume. A falta de reconhecimento da escola não se reflete apenas na crise que a educação atravessa em nosso país, mas, também, no tratamento (leia-se investimento) que se aplica aos seus espaços físicos, dentre eles os arquivos escolares. Para nós, pesquisadores da área, que nos deparamos com documentos nos locais mais improváveis (armários em salas de aula, dividindo prateleiras com instrumentos musicais, amontoados em depósitos de produtos de limpeza, ou ao lado das cozinhas onde se prepara a merenda escolar) sabemos que as verbas públicas passam muito longe destes. 
Figura 1: Arquivo Escolar do Colégio Estadual de Itaberaba.

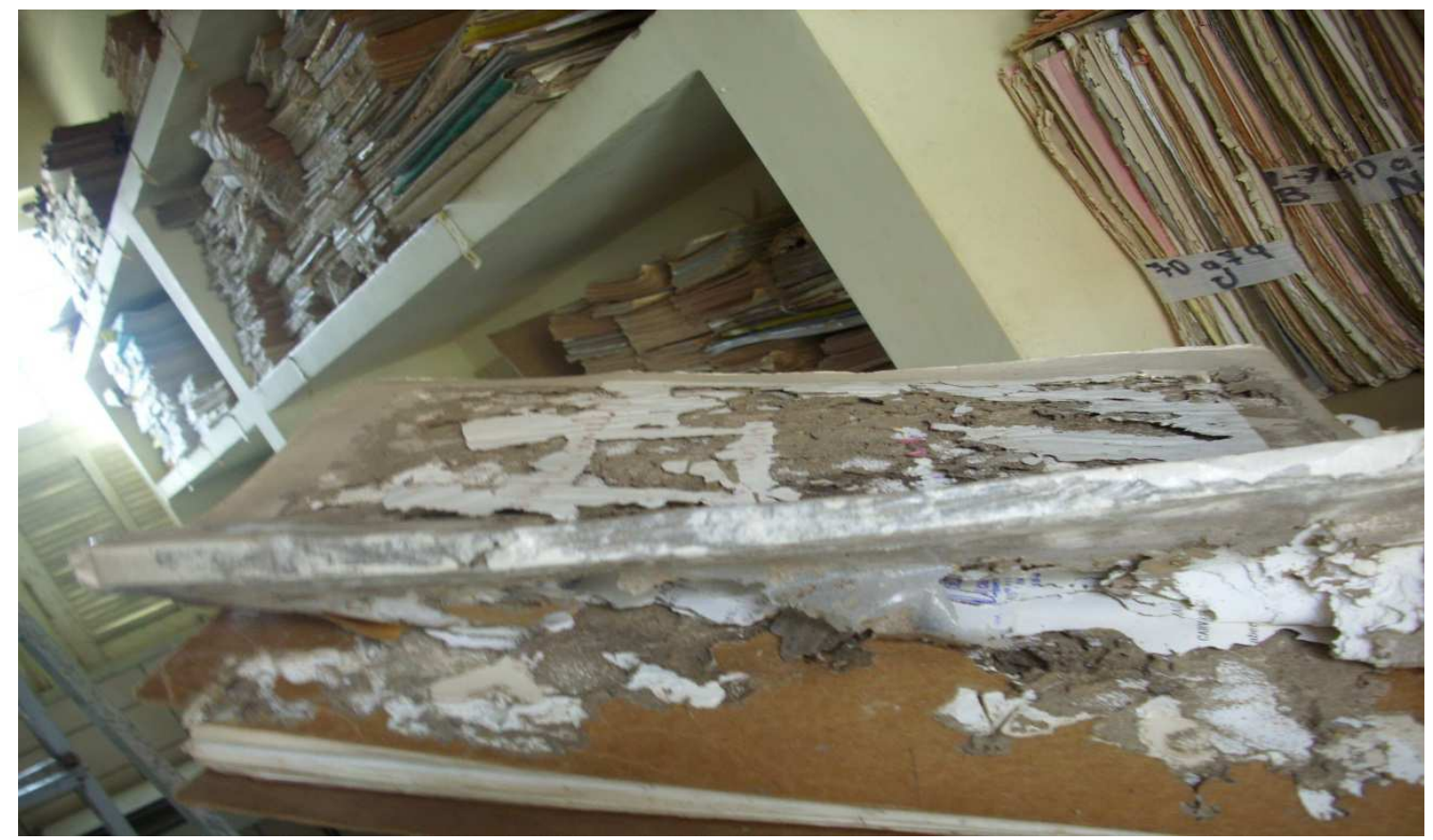

Fonte: Acervo do Grupo Memória da Educação.

Quanto aos pesquisadores, em especial os historiadores, como afirma Le Goff (1990) o passado que sobrevive e que se apresenta no presente "não é o conjunto daquilo que existiu, mas uma escolha efetuada quer pelas forças que operam no desenvolvimento temporal do mundo e da humanidade, quer pelos que se dedicam à ciência do passado e do tempo que passa." (1990, p. 535). Como escolha, o espaço escolar, no Brasil, ainda é bastante desconsiderado pelos representantes de Clio. Um historiador que elege a escola e a educação como objeto investigativo precisa seguir seus estudos, geralmente, em programas de pósgraduação stricto sensu em Educação, visto que os mestrados e doutorados de História, em sua maioria, não oferecem linhas de pesquisa que considerem a Escola um importante objeto e local para as pesquisas historiográficas.

\section{AS AÇÕES E O TRATAMENTO DAS FONTES}

O projeto Missões de Pesquisa: levantamento e catalogação de fontes tem como principal objetivo mapear e organizar um banco de dados com fontes sobre História da Educação no interior da Bahia e disponibilizá-las para a promoção de pesquisas científicas na temática. Entendemos que um dos fatores que contribuem para o pequeno número de 
pesquisas sobre a História da Educação e do Ensino em nossa região é o fato de os jovens historiadores não conhecerem a existência de tais fontes.

Outros objetivos secundários também podem ser destacados, como: a mobilização e conscientização dos graduandos em relação aos locais de trabalho dos Professores/ Historiadores, a formação e capacitação dos graduandos no trato com documentos de arquivos e sobre História da Educação e o fortalecimento das pesquisas em Educação e Ensino no Campus VI da Universidade do Estado da Bahia.

Figura 2: Arquivo do Núcleo Regional de Educação 12.

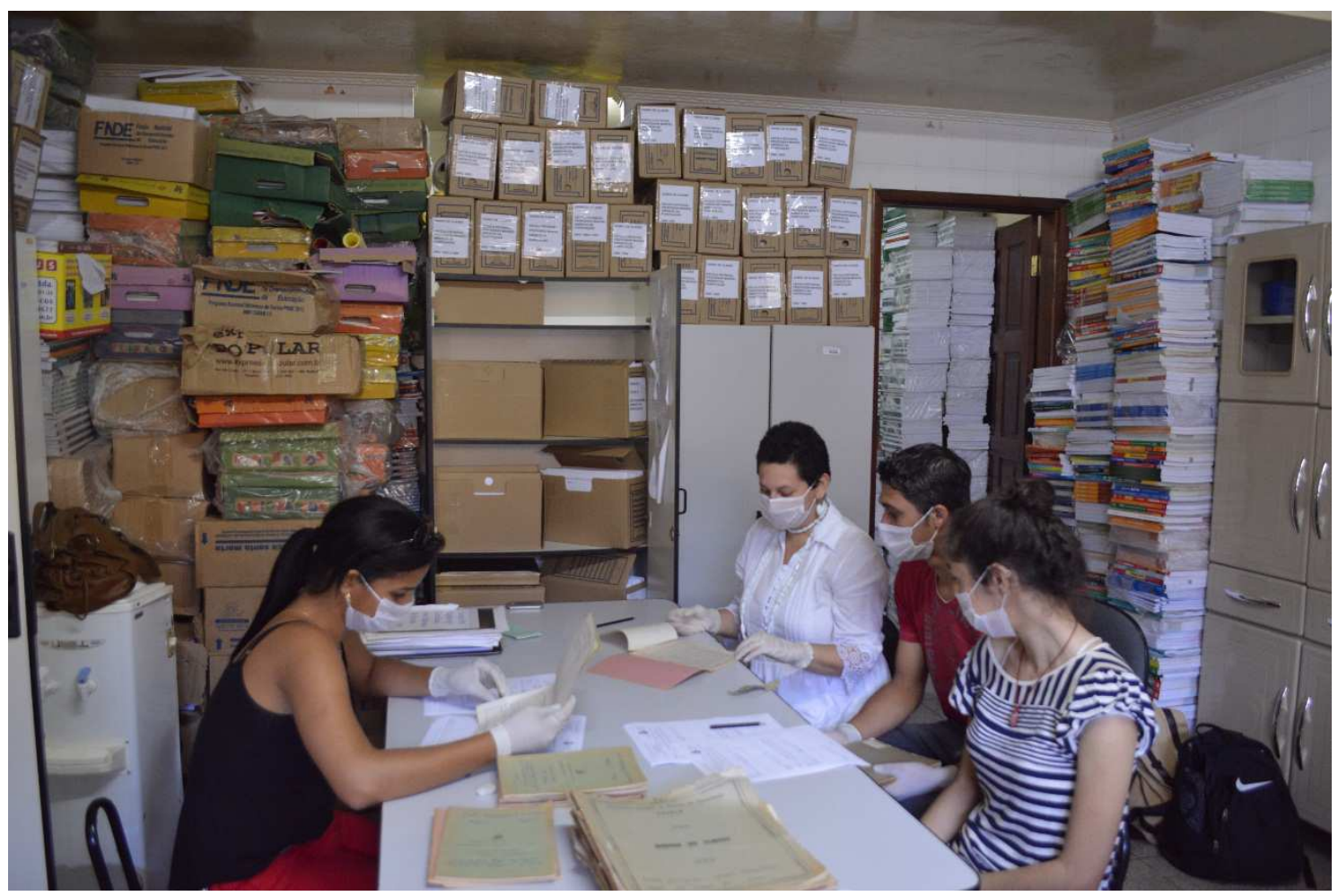

Fonte: Acervo do Grupo Memória da Educação.

A busca das fontes ocorreu, inicialmente, em cidades do entorno do Campus VI. Na cidade de Rio de Contas foram realizadas duas visitas ao Arquivo Municipal de Rio de Contas e uma visita à Escola Barão de Macaúbas; na cidade de Macaúbas as Missões se concentraram no Núcleo Regional de Educação 12, na fundação Cultural Professor Mota e no Acervo Particular do professor Ático Vilas Boas, além do Arquivo Público Municipal; em Igaporã, visitamos o Colégio Estadual José Rocha. Os próximos levantamentos estão previstos para o Arquivo Municipal de Lençóis, o Arquivo Municipal de Mucugê e as escolas mais antigas do município de Palmas de Monte Alto. 
Em Caetité, sede do Departamento de Ciências Humanas - Campus VI, o grupo priorizou as atividades no Núcleo Regional de Educação 13, com a catalogação da documentação das escolas extintas do município de Licínio de Almeida² e com a salvaguarda de livros didáticos antigos que foram cedidos para o LAPEDHI.

Figura 3: Livro de Atas de Exames de Admissão do Ginásio Normal Carlos França.

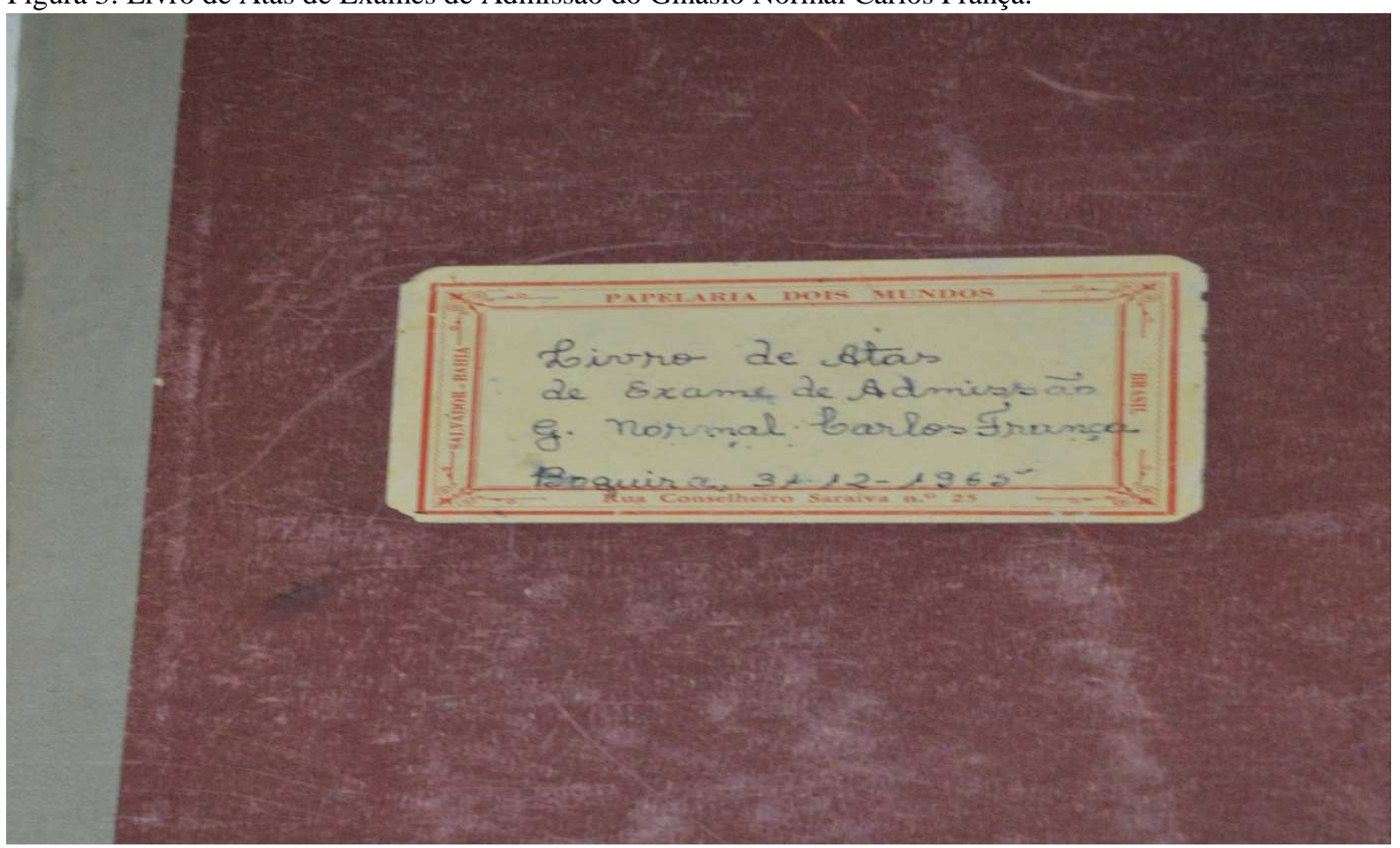

Fonte: Arquivo do Núcleo Regional de Educação 12 - Macaúbas.

Consideramos que existe uma necessidade concreta para tais ações, já que a História da Educação do interior baiano está por se fazer, pois os dois maiores núcleos de pesquisa na temática na Bahia são: o História da Educação na Bahia (HISTEDBA) na Universidade do Sudoeste da Bahia, em Vitória da Conquista e o Projeto Memória da Educação na Bahia (PROMEBA), da Universidade do Estado da Bahia, em Salvador. Todavia, estes grupos ainda não contemplam a enorme quantidade de sujeitos, objetos e problemáticas que a História da Educação da Bahia resguarda, em especial em seu interior.

\footnotetext{
${ }^{2}$ Com a reestruturação administrativa realizada pelo Governo do Estado da Bahia, as DIRECs - Diretoria Regional de Educação se tornam NRs - Núcleos Regionais de Educação, sendo enxutos em um número menor e concentrando mais municípios por núcleo. Neste processo, algumas cidades terão suas sedes administrativas mudadas e, consequentemente, a documentação das escolas extintas seguirão para os novos municípios. Assim, os documentos das escolas de Licínio de Almeida, que estavam sob a guarda da Direc 24 de Caetité, seguirão para o município de Vitória da Conquista.
} 
As atividades de levantamento de fontes históricas repercutem de maneira bastante positiva entre os graduandos. A maioria "descobre" o potencial das pesquisas relacionadas à temática e, mesmo os que não desenvolvem trabalhos de conclusão relacionados ao tema, reconhecem que a Educação e o Ensino de História ou de outra área são objetos de investigação histórica. A seguir, apresentamos nosso instrumento de catalogação das fontes:

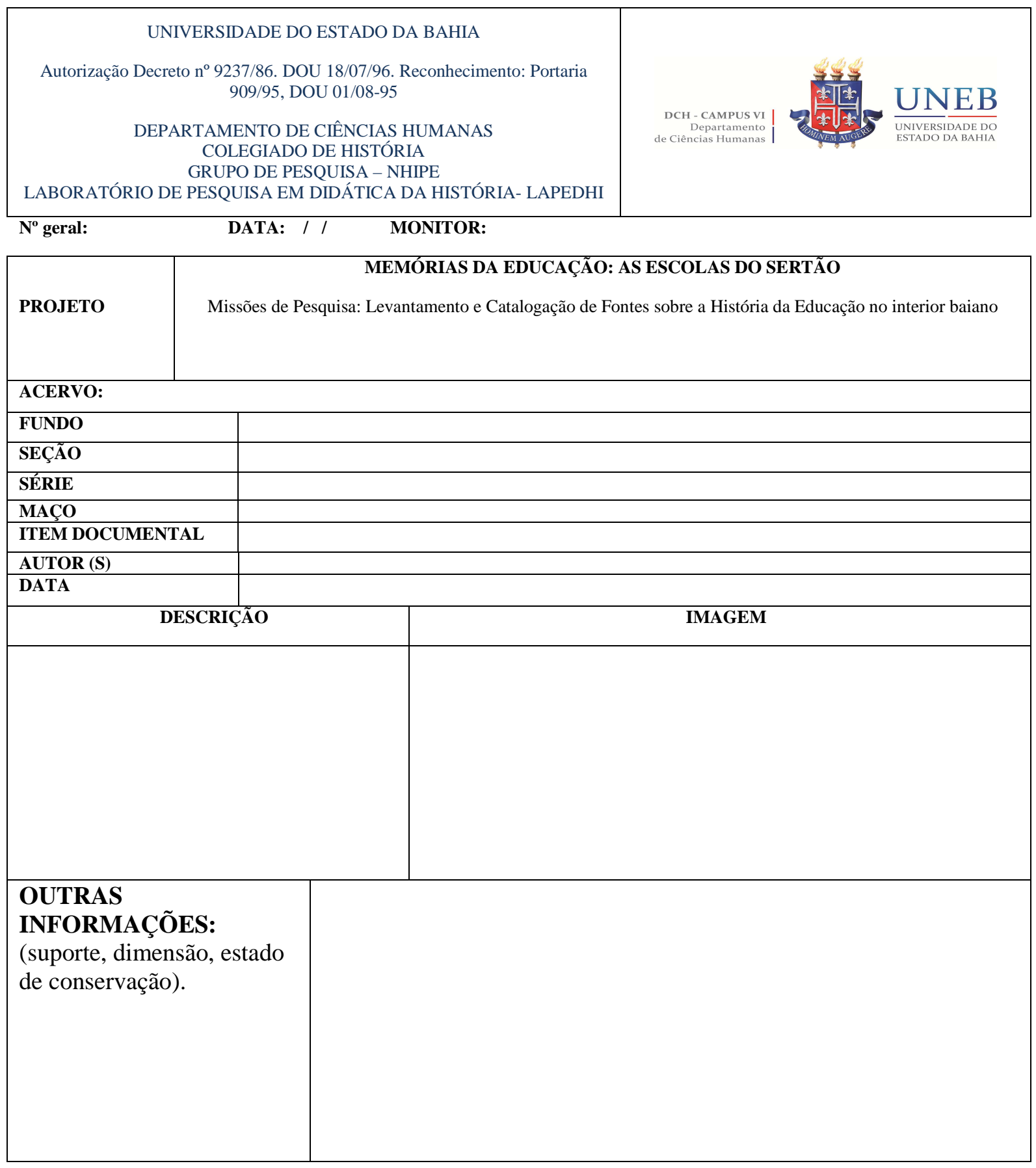


Para a catalogação, uma ficha foi elaborada visando a organização do trabalho e a garantia do rigor científico. Nela constam itens de identificação do projeto e do monitor responsável pelo preenchimento dos dados; elementos para orientação das referências em que o documento pode ser localizado conforme os critérios de arquivamento da instituição, o tipo de documento, data e autores; por fim, o assunto tratado pela documentação, sendo que o responsável precisa escrever sucintamente o teor do documento. Ao lado da descrição é reservado um espaço para a imagem do documento.

Este exercício de catalogação proporciona aos estudantes uma iniciação fundamental para o ofício do historiador, criando uma "intimidade" com as habilidades de pesquisa. Outro aspecto importante nesta atividade consiste em perceber a diversidade de lugares que abrigam fontes para a História da Educação. A sistematização das informações revelou uma fonte expressiva para a temática: os jornais.

Nas páginas dos tabloides das cidades do interior, no final do século XIX e primeira metade do século XX, o cotidiano da sociedade se apresenta sob vários aspectos. No caso específico da vida das escolas, é possível encontrar informações sobre matrículas, chamada para exames finais, portarias, decretos e resoluções referentes ao funcionamento das escolas, notícias sobre formaturas, eventos cívicos e atividades festivas, matérias de opinião assinadas por professores, diretores e outros representantes da sociedade. Além das fotografias que nos informam sobre a arquitetura escolar, os uniformes, as cerimônias cívicas, as pessoas, entre outros.

O acesso a esta gama de possibilidades qualifica a trajetória profissional do estudante, ampliando sua visão sobre a escola e construindo organicamente a relação ensino e pesquisa.

\section{A PESQUISA SOBRE HISTÓRIA DA EDUCAÇÃO NO INTERIOR DA BAHIA E SUAS POSSIBILIDADES}

Nas ações já realizadas pelo Projeto Missões, alguns resultados se destacam, entre eles: o levantamento de fontes que possibilitam estudos sobre diversos temas, ampliação de projetos de pesquisa entre os estudantes de graduação e o estabelecimento de intercâmbios com outros grupos de pesquisa, em especial o PROMEBA / UNEB e o Grupo de Estudo e Pesquisa e Ensino de História - GEPENH / UEFS. 
Quanto aos projetos de pesquisa que encontram amparo no Projeto Missões, ampliando suas abordagens em função das fontes levantadas, temos:

Quadro I: Projetos de pesquisa sobre História da Educação.

\begin{tabular}{|c|c|c|}
\hline NATUREZ & AUTORES & PESQUISA \\
\hline $\begin{array}{l}\text { TCC } \\
\text { GRADUAÇÃO }\end{array}$ & $\begin{array}{l}\text { Eliseu Rodrigues da } \\
\text { Silva }\end{array}$ & $\begin{array}{l}\text { A atuação das professoras } \\
\text { alfabetizadoras do MOBRAL }\end{array}$ \\
\hline $\begin{array}{l}\text { TCC } \\
\text { GRADUAÇÃO }\end{array}$ & Graciela Matos & $\begin{array}{l}\text { Intelectuais } \text { negros na } \\
\text { República: ascensão social a partir da } \\
\text { profissão docente }\end{array}$ \\
\hline $\begin{array}{l}\text { MONOGRAFIA - - } \\
\text { ESPECIALIZAÇÃO }\end{array}$ & Vânia Muniz dos Santos & $\begin{array}{l}\text { A representação de negros e } \\
\text { indígenas nos livros didáticos e } \\
\text { currículos de Organização Social e } \\
\text { Política Brasileira e Educação Moral e } \\
\text { Cívica }\end{array}$ \\
\hline $\begin{array}{l}\text { INICIAÇÃO } \\
\text { CIENTÍFICA } \\
\text { GRADUAÇÃO }\end{array}$ & $\begin{array}{l}\text { Vânia Muniz dos Santos } \\
\text { Maryana Gonçalves } \\
\text { Souza }\end{array}$ & $\begin{array}{l}\text { Possibilidades de pesquisas } \\
\text { históricas em instituições escolares no } \\
\text { Alto Sertão Baiano: Centro Educacional } \\
\text { de Pindaí (1975-1985) }{ }^{3} \text { - Este projeto } \\
\text { está em fase final e apresentará como } \\
\text { resultado um catálogo de fontes sobre a } \\
\text { referida escola. }\end{array}$ \\
\hline $\begin{array}{l}\text { INICIAÇÃO } \\
\text { CIENTÍFICA } \\
\text { GRADUAÇÃO }\end{array}$ & $\begin{array}{l}\text { Maryana Gonçalves } \\
\text { Souza }\end{array}$ & $\begin{array}{l}\text { Colégio Estadual Governador } \\
\text { Luiz Viana Filho: instituição, arquivo } \\
\text { escolar e possibilidades de pesquisa } \\
(1956-1994)\end{array}$ \\
\hline $\begin{array}{l}\text { INICIAÇÃO } \\
\text { CIENTÍFICA } \\
\text { GRADUAÇÃO }\end{array}$ & $\begin{array}{lll}\text { Eliseu } & \text { Rodrigues } \\
\text { Silva } & & \end{array}$ & $\begin{array}{l}\text { O MOBRAL e a alfabetização } \\
\text { de adultos na ditadura: possibilidades de } \\
\text { pesquisa através de documentos } \\
\text { escolares (1970-1980) }\end{array}$ \\
\hline
\end{tabular}

${ }^{3}$ Projeto de autoria da professora Luciana Oliveira Correia. 
Com a organização em banco de dados das informações coletadas e sua disponibilidade em ambiente virtual para acesso irrestrito da sociedade, acreditamos que as pesquisas sobre a temática da História da Educação e do Ensino no Departamento de Ciências Sociais - Campus VI aumentarão, ampliando o conhecimento sobre a vida escolar no interior baiano.

Acerca das possibilidades elencadas a partir das fontes já catalogadas, exemplificamos:

Quadro II: Documentos e suas possibilidades de pesquisa na História da Educação.

\begin{tabular}{|c|c|}
\hline DOCUMENTOS & POSSIBILIDADES \\
\hline Separação de turmas por sexo; & Cultura Escolar \\
\hline $\begin{array}{l}\text { Registros de bens e livros do Grupo } \\
\text { Escolar Barão de Macaúbas e da Sociedade } \\
\text { do Clube Rio Contense. }\end{array}$ & Cultura Material; \\
\hline $\begin{array}{l}\text { Documentos } \text { do } \quad \text { Internato } \\
\text { Sant'Anna, Documentos do Grupo Escolar } \\
\text { Barão de Macaúbas. }\end{array}$ & $\begin{array}{llll} & \text { Memórias de instituições } \\
\text { Escolares; } & & & \\
& & & \end{array}$ \\
\hline Jornal Luzeiro Infantil $^{4}$ & $\begin{array}{l}\text { Metodologias de Ensino nas } \\
\text { escolas; }\end{array}$ \\
\hline Livros didáticos de várias épocas & $\begin{array}{l}\text { Metodologias e ideias difundidas } \\
\text { nas escolas através de livros didáticos } \\
\text { oficiais; }\end{array}$ \\
\hline Cadernetas & $\begin{array}{l}\text { Público escolar, condição social } \\
\text { dos alunos, etc; }\end{array}$ \\
\hline Dossiês de Alunos & $\begin{array}{l}\text { Práticas Pedagógicas, público } \\
\text { escolar, temas para a História Social e } \\
\text { Cultural, etc; }\end{array}$ \\
\hline $\begin{array}{l}\text { Jornal O Pequeno, matéria intitulada } \\
\text { "O analfabetismo no Sertão". }\end{array}$ & 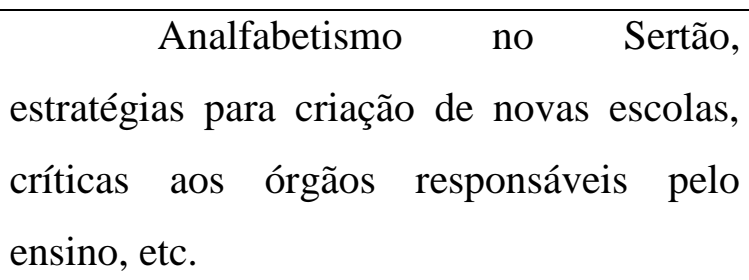 \\
\hline
\end{tabular}

\footnotetext{
${ }^{4}$ Esse jornal era escrito pelos diretores da Escola Barão de Macaúbas e além de matérias sobre a vida escolar, discorria sobre os métodos de ensino da escola.
} 


\begin{tabular}{|c|c|}
\hline Iconografias Diversas & $\begin{array}{l}\text { Cotidiano e cultura escolar, } \\
\text { organização de classes, História da } \\
\text { Educação de jovens e adultos, interação } \\
\text { entre escola e comunidade escolar, etc. }\end{array}$ \\
\hline Livros de Regras & $\begin{array}{l}\text { Regulamentação Escolar, normas } \\
\text { e doutrinas criadas na e para a escola, } \\
\text { estruturas de calendário escolar, etc. }\end{array}$ \\
\hline $\begin{array}{l}\text { Artigos de Jornais: O Cinzel, O } \\
\text { Riocontense, e o O Pequeno }\end{array}$ & $\begin{array}{l}\text { Formação moral que a escola } \\
\text { exercia no início do século XX, separação } \\
\text { entre Estado e Igreja, secularização da } \\
\text { Educação, cultura escolar, cultura material } \\
\text { escolar, movimentação do corpo docente, } \\
\text { críticas e elogios às escolas, entre outros } \\
\text { temas. }\end{array}$ \\
\hline
\end{tabular}

Essas são apenas algumas das possibilidades e dos resultados que já obtivemos. É válido ressaltar que as fontes levantadas ainda não foram analisadas profundamente a fim de elencar possibilidades mais concretas para a pesquisa e que este quadro é apenas uma exemplificação do material que já temos disponível no LAPEDHI.

É preciso pontuar ainda que esse quadro de possibilidades destacadas, diz respeito aos documentos catalogados no Arquivo Municipal de Rio de Contas, sendo que, por enquanto, ainda não se realizou uma apuração mais detalhada das fontes obtidas na viagem ao Município de Macaúbas e das visitas ao NR-13.

Mais adiante, com a criação do ambiente virtual, estas informações ficarão disponibilizadas, indicando a relação de documentos catalogados e o local onde se encontram e permitindo aos pesquisadores mapearem suas fontes e sua localização. Em longo prazo, pretendemos realizar a publicação um catálogo com alguns documentos encontrados e com pesquisas realizadas através das Missões.

As próximas atividades do grupo Missões contam com viagens para municípios circunvizinhos ao Campus VI e da Chapada Diamantina, além da aplicação de oficinas de formação sobre o trato com iconografias e livros antigos, tendo em vista formar e capacitar os 
alunos participantes das Missões e funcionários de escolas parceiras ${ }^{5}$ para lidar com os documentos escolares.

A aplicação de oficinas não fica restrita aos monitores e funcionários das escolas parceiras na sede do município de Caetité, serão aplicadas também oficinas de sensibilização quanto à importância dos arquivos escolares para secretários e diretores das escolas ligadas ao NR-13, discutindo a situação precária em que se encontram os arquivos escolares e a necessidade de conscientização de toda a comunidade escolar para com esse importante patrimônio que resguarda a história da instituição da qual faz parte e de toda uma época, sendo assim importante, não só a para a História da Educação como para a História Social.

Outra atividade é o recrutamento de novos monitores para o projeto, em especial, de outras áreas do saber, como: Letras, Matemática, Ciências Biológicas, Geografia, entre outros cursos, que tenham a curiosidade e o desejo de trabalhar com a História da Educação e do Ensino, para maior ampliação e integração das pesquisas na área numa visão de interdisciplinaridade.

\section{CONSIDERAÇÕES FINAIS}

Diante das perspectivas apresentadas, concluímos que o Projeto Missões de Pesquisa: levantamento e catalogação de fontes sobre a História da Educação no interior baiano, responde a inúmeras inquietações dos pesquisadores em História da Educação no Campus VI da UNEB, pois realiza um trabalho que ao inventariar fontes e documentos para esta área do saber, promove o Ensino, a Pesquisa e a Extensão, sendo assim indispensável para a manutenção dos trabalhos nessa temática e buscando valorizar não só os documentos de arquivos oficiais e institucionais, como também os arquivos escolares e pessoais que são indispensáveis no estudo das instituições escolares e de sua repercussão.

Sendo assim, cremos que as ações deste grupo são importantes para a valorização dessa gama de documentos e temos motivos para acreditar que as próximas visitas aos arquivos, bem como, a realização das oficinas sobre documentos iconográficos e sobre a importância dos arquivos escolares nos darão maiores possibilidades e potencialidades de realizar investigações sobre o patrimônio histórico educativo do interior baiano e sobre sua importância para a História da Educação da Bahia e do Brasil, através do cruzamento de

\footnotetext{
${ }^{5}$ Estas escolas aqui referidas, são: o Centro Territorial Profissionalizante de Educação do Sertão ProdutivoCETEP e o Grupo Escolar Monsenhor Bastos
} 
fontes e da verificação de análises comparativas. Além disso, visamos contribuir de forma significativa para a difusão dessas pesquisas através do ambiente virtual e das publicações a serem lançadas com o material produzido.

\section{REFERÊNCIAS}

ARQUIVO NACIONAL. Identificação de documentos em arquivos públicos. Rio de Janeiro, 1985.

BELLOTTO, Heloísa Liberalli. Arquivos permanentes: tratamento documental. São Paulo, T. A. Queiroz, 1991.

BURKE, P. (Org). A escrita da história: novas perspectivas. São Paulo: UNESP, 1992.

CARRETERO, M; ROSA, A; GONZÁLEZ, M. F. (Org) Ensino da história e memória coletiva. Porto Alegre: ARTMED, 2007.

DELGADO, J. R. Presupuestos básicos para la investigación histórico-educativa. Revista de Educación, 7 (2005). ISSN: 1575 - 0345. Universidad de Huelva, 2009.

FARIA FILHO, L; M; VIDAL. D. G; PAULILO, A. L. A cultura escolar como categoria de análise e campo de investigação na história da educação brasileira. Educação e Pesquisa. São Paulo, v. 30, n. 1, p. 139-159, 2004.

FIGUEIREDO, Betânia Gonçalves. Patrimônio Histórico e Cultural: um novo campo de ação para os professores. In: GRUPO Gestor do Projeto de Educação Patrimonial. Reflexões e contribuições para a Educação Patrimonial. Belo horizonte: SEE/MG (Lições de Minas, 23). 2002.

JULIA, D. A cultura escolar como objeto histórico, In: Revista Brasileira de História da Educação, Campinas, n. 1, p. 9-44, 2001.

LE GOFF, Jacques. História e memória. Campinas, SP: Editora da UNICAMP, 1990.

MOGARRO, Maria João. Arquivos e educação: a construção da memória educativa. In: Revista Brasileira de História da Educação, n. 10, p. 75- 99, jul./dez. 2005. Disponível em: <http://rbhe.sbhe.org.br/index.php/rbhe/issue/view/17>. Acesso em: 23 maio 2014.

VELASCO MAILLO, Honorio M. FOTOGRAFIAS ESCOLARES, IMAGÉNES INSTITUCIONALES: Miradas retrospectivas a la fotografia em laescuela (1900-1970), In: Antropología audiovisual: medios e investigacióneneducación. Coordinadores: AntonioBautista García-Vera y Honorio M. Velasco Maillo. Trotta, 2011, 272p. 